\title{
Predictors of Consistent Condom and Voluntary Counselling and Testing Services Utilization Among BodaBoda Operators in Coastal Region of Kenya
}

\author{
Shadrack Ayieko Yonge ${ }^{1,}$, , Michael Fredrick Otieno², Rekha Rani Sharma ${ }^{3}$ \\ ${ }^{1}$ Department of Environment and Health Sciences, Technical University of Mombasa, Mombasa, Kenya \\ ${ }^{2}$ Department of Medical Laboratory Sciences, Kenyatta University, Kahawa, Kenya \\ ${ }^{3}$ Department of Zoological Sciences, Kenyatta University, Kahawa, Kenya
}

Email address:

shadrackyongez@yahoo.co.uk (S. A. Yonge)

${ }^{*}$ Corresponding author

\section{To cite this article:}

Shadrack Ayieko Yonge, Michael Fredrick Otieno, Rekha Rani Sharma. Predictors of Consistent Condom and Voluntary Counselling and Testing Services Utilization Among BodaBoda Operators in Coastal Region of Kenya. Science Journal of Public Health.

Vol. 5, No. 3, 2016, pp. 152-161. doi: 10.11648/j.sjph.20170503.11

Received: January 19, 2017; Accepted: February 8, 2017; Published: March 1, 2017

\begin{abstract}
Despite recent declines in global HIV/AIDS mortality, HIV/AIDS is still the leading cause of death especially in in Sub-Saharan Countries. Voluntary HIV counseling and testing (VCT) and consistent condom use among BodaBoda operators are very important in the prevention and control of the infection. This study determined the consistent condom and voluntary counseling and testing services utilization among BodaBoda operators in Coastal region of Kenya. A cross-sectional study was carried between February to December 2015. A multi-stage sampling method was applied to randomly select the BodaBoda operators. Stratification, random and systematic sampling techniques were used to identify the study participants. Interviews were conducted using structured questionnaires. Data analysis was done using statistical package for social sciences version 16. Analytical statistics were done using odds ratio to measure strength of association between Condom and VCT uptakes and independent variables. Association with p-value $<0,05$ was considered significant. Binary regression was used to identify predictors of condom and VCT uptakes. Of 385 participants, 98.7\% were male and 1.3\% female. This study revealed that the prevalence of VCT uptake and consistent condom use among BodaBoda operators in Coastal Kenya was 53.0\% and 60.0\% respectively. VCT uptake was found to be significantly predicted bygender (AOR=3.216, 95\% CI: 1.410-9.964), visiting a VCT centre with a partner $(\mathrm{AOR}=16.39,95 \% \mathrm{CI}: 3.012-17.624)$, assurance of confidentially of $\mathrm{HIV}$ test results $(\mathrm{AOR}=4.79,95 \% \mathrm{CI}$ : 2.033-8.907), known VCT (AOR=0.152, 95\% CI: 0.034-0.221) and fear of being seen at VCT centre $(\mathrm{AOR}=0.551,95 \% \mathrm{CI}$ : 0.307-0.988). Consistent condom use was significantly associated with gender (AOR=2.01, 95\% CI: 1.04, 2.48), Educational status ( $\mathrm{AOR}=0.80,95 \% \mathrm{CI}: 0.43,0.85)$ and marital status (AOR=1.51, 95\% CI: 1.07-2.15). Conclusion: The overall prevalence of VCT uptake and consistent condom use was found to be low. VCT utilization uptake among the operators was influenced by gender, assurance of confidentiality of the HIV test results, going to a VCT with a partner, fear of being seen at a VCT centre and going to a known VCT. The main predictors of consistent condom use were found to be gender, educational level and marital status. Integration of friendly VCT services would increase VCT uptake among BodaBoda operators. Support and care received after knowing the test results should be clearly communicated as it reduces stigma. Therefore, interventions targeting sex, educational status and marital status are recommended.
\end{abstract}

Keywords: VCT Uptake, Consistent Condom Utilization, Predictors, HIV Test

\section{Introduction}

The HIV/AIDS epidemic is a growing public health problem in Kenya. The epidemic has extended beyond the commonly the commonly classified high-risk groups and now is common in the general population. The pandemic continues to spread globally: a total of 37.6 million people were infected 
with HIV worldwide in 2013 [1]. Sub-Saharan Africa remains the most affected region; 26.4 million people were estimated to be living with HIV and approximately 2.3 million new infections in 2013. The region also accounted for $72 \%$ of the world's AIDS-related deaths in 2014 [2] The Joint United Nations Program on HIV/AIDS (UNAIDS) estimates that around4 million between ages 15-49 are living with HIV and AIDS in Kenya [3]. Roughly 58,000 people died from AIDSrelated illness in the same year. Heterosexual transmission is the main portal of entry of HIV in Kenya. While awareness on $\mathrm{HIV}$ is relatively high especially among urban populations, it appears that the high level of knowledge of HIV has little impact on myths and misconceptions about HIV transmission [4]. Risky sexual practices have been reported in several subpopulations such as young person's [5], commercial sex workers [6] and commercial drivers [7] thus indicating the need for improved intervention programs in these populations. Despite the rapidly spreading of HIV/AIDS epidemic many people practice unsafe sex even when they know that using condoms correctly and consistently prevents sexually transmitted infections HIV/AIDS [8]. A study done in a cambodian hospital, Phnom Penh shows that most (61\%) of HIV infected male patients were unaware of their risk for HIV infection through their sexual behaviours with commercial sex workers without condom use [9]. Studies comparing condom use among women who had access to both male and female condoms and those with access to male condoms alone have shown that female condom availability does not increase protection [10-12]. Voluntary Counselling and Testing program has proved effective in the fight against HIV/AIDS and serves as an entry point to HIV with positives - the use of the HIV infected individuals to help stop the spread of the virus [13]. Voluntary Counselling and Testing forms a link to HIV treatment options, care and support as it allows for adoption of preventive measures [14]. People are safer when they know their HIV status [15]. By knowing one's status, HIV positive individuals are motivated to adopt healthier lifestyles like eating healthy food and reducing stress thus improving their health and slowing disease progression to symptomatic HIV and full blown AIDS [16] Voluntary Counselling and Testing thus forms a major tool in the prevention of HIV/AIDS especially among high risk groups. Taking an early step to visit a VCT centre can lead to prolonging of life when a decision of positive living is adopted on accurate knowledge of one's current HIV status. According to UNAIDS [17] report, more than $80 \%$ of PLWHA in low income countries do not know they are infected including the transport providers like taxi drivers [18] and BodaBoda operators [19]. Among the transport providers, risk behaviours are fostered by trade for sex, constant cash flow and high sexual activity. It is for this reason that taxi drivers [20] and other transport operators like BodaBoda operators call for more HIV testing and counselling services. Voluntary Counselling and Testing is therefore a useful tool in stemming up HIV/AIDS pandemic that continues to spread globally. According to the suggestions of WHO, a combination of approaches are very important to prevent the sexual transmission of HIV, including correct and consistent condom use, reduction in the number of sexual partners, HIV testing and counseling, delay sexual debut, treatment for STIs and male circumcision [21]. Negative attitudes towards using male condoms and VCT services tend to be associated with high rates of sexual risk. Little has been written about the factors that influence condom and Voluntary Counselling and Testing Services Utilisation, and this has implications for HIV intervention efforts. Understanding factors associated with safer sexual practices and condom use among bodaboda operators is considered a vital component of HIV/AIDS prevention strategies. In this article, We assessed the predictors of consistent condom and voluntary counselling and testing services utilisation among BodaBoda Operators in Coastal Region of Kenya. Such information can help improve the design of intervention campaigns to reduce the spread of HIV in this group, among high-risk groups and the general population.

\section{Materials and Methods}

\subsection{Study Area}

The study was conducted in Mombasa County which has a population of $1,031,266$ by the year 2012 . The population is steadily growing due to rural-urban migration and immigration from unstable countries. The total area Mombasa is 109 $\mathrm{Km}^{2}$ with about $60 \%$ of the people living overcrowded informal settlements in the form of shelters. Residents are of mixed ethnicity and are engaged in low-income generating activities, mainly informal sector and small trading. The County has rapid population growth and is characterized by low socio-economic indicator. This creates huge demands on health facilities and inability to keep pace with the environment, continued economic prosperity, public health and quality of life of residents. Tuberculosis and HIVAIDS are the leading causes of deaths in the area representing $50 \%$.

\subsection{Study Population}

The study population consisted of BodaBoda operators within Mombasa County. These are men and women who earn their living by transporting passengers and/or goods by motorcycles in exchange for money. BodaBoda business is the major means of transport in this area is fast due to traffic jam and cheap. Moreover, BodaBoda operators in this region are a population that is at risk of HIV infection.

\subsection{Study Design}

This was descriptive cross-sectional study carried out between February 2015 to December 2015. It was carried out to provide a snap-shot (one point measurements). Both quantitative and qualitative methods were used to collect data

\subsection{Inclusion and Exclusion Criteria}

\subsubsection{Inclusion Criteria}

The following criteria were used to recruit participants to the study. 
a) Must have been practicing as a BodaBoda operator within Mombasa Countyfor at least three months.

b) Those who consented to participate in the study

\subsubsection{Exclusion Criteria}

Those had less than three months of operational and did consent

\subsection{Sample Size Determination}

The sample size was arrived at by calculation using Fisheret al.(1983)standard formula asshown below.

$$
N=\frac{Z^{2} p q D}{d^{2}}
$$

Where $\mathrm{N}=$ minimum required sample size when target population was greater than 10,000$)$

$Z$ =standard normal deviate (1.96) which corresponds to $95 \%$ confidence level.

$p=$ proportion of the target population estimated to be bodaboda operators was assumed to be $50 \%(0.5 \%)$

$q=1-p$ (proportion in the target population that do not have

Non bodaboda operators $=0.5(1-p)$

$d=$ degree of precision desired $=0.05$

$D=$ design effect $=1$

Thus,

$$
\mathrm{N}=\frac{(1.96)^{2} \times 0.5 \times 0.5}{(0.05)^{2}}=385
$$

\subsection{Sampling Procedure}

Mombasa County was purposively sampled because of high number of bodaboda operators who are at high risk of contracting HIV virus. The sampling frame consisted of all the terminus within the study area. After the selection of the study terminus, each was allocated a proportionate number of study subjects based on the bodaboda population. A sample frame consisting of the names of operators was made for each of the terminus from the operators' daily registers. These sample frames are the ones from which the operators were selected. A sampling interval was designed in each of the sample frames by dividing the total number of operators in that terminus by the sample size of each terminus. After which a random starting point in the sample frame was determined. Study participants (operators) were then selected with the predetermined sampling interval as they came to the parking bay daily. This was done until the required sample size was reached. This was replicated throughout all the parking bays in all the respective centres. The total number of participants included in the study was sum of all sampled participants from all the termini.

\subsection{Data Collection Procedures}

Data collectors were recruited from the county and the minimum qualification was successful completion of form four. Data was collected using a self-administered structured questionnaire which was adopted and modified from reviewed literatures

\subsubsection{Piloting}

Questionnaires were piloted in one the terminus which was subsequently excluded from the survey. The result of the pre-test was discussed and some corrections and changes were made on the questionnaires before the actual data collection.

\subsubsection{Qualitative Methods}

To supplement the quantitative data from individual respondent interviews, five in-depth focus group discussions were conducted chairman of operators association, community health workers and NACC coordinator. Each group consisted of between 8 and 10 participants with the principal investigator leading the discussions.

\subsubsection{Quantitative}

Pre-tested interviewer administered questionnaires was used to collect data.

\subsubsection{Quality Control}

The investigator was responsible for overall co-ordination and conducting of research. The questionnaires were pretested and administered by trained research assistants in order to reduce errors. There was regular checking of filled questionnaires for completeness and appropriatenes.

\subsection{Ethical Consideration}

The proposal for this study was approved by Kenyatta University Ethical Review Committee. It was approved by the ministry of education, Science and Technology (MOEST). Informed consent was obtained from the subjects before they were enrolled into study. The purpose of this study was explained to the subjects in English and Kiswahili. Code numbers rather than nameswere used to identify them in order to maintain confidentiality.

\subsection{Data Management and Analysis}

Data were double-entered onto the EPI-data version 3.1 softwareby defining legal values for each variable and setting skip patterns. The double-entered data were validated and exported to SPSS software (version 16.0; SPSS Inc., Chicago, USA). Univariate and bivariate analysis were computed to see the frequency distribution and to test whether there is association between consistent condom and VCT utilisation with selected independent variables. Factors associated with consistent condom and VCT utilisation at bivariate were identified. Finally, we conducted a model likelihood ratio test to determine the goodness of fit of the model. Adjusted prevalence odds ratio (APOR) with $95 \% \mathrm{CI}$ was computed for each association. Variables with p-value of 0.20 and less were taken to multivariable analysis. Finally, the p-values less than 0.05 were considered statistically significant. 


\section{Results}

\subsection{Socio-demographic Characteristics of the BodaBoda Operators in Mombasa County}

A total of 385 BodaBoda operators were enrolled in this study at the study terminus. In terms of gender, 380 (98.7\%) were males and $5(1.3 \%)$ females. Their ages were between
18 and 80 years and median age being 32 years. The majority (42.4\%) of the participants were in the 25-34 age-group, followed by those in the 35-44 (24.4\%), 18-24 (19.2\%), 45$54(9.8)$ and $55+(3.4 \%)$ age groups respectively. Almost $85 \%$ had attained secondary and college of education while $14.6 \%$ primary level. Over a half $(54.2 \%)$ of the participants were married while $(38.4 \%)$ were not married (Table 1$)$.

Table 1. Socio-demographic Characteristics of the BodaBoda operators in Coastal Region, Kenya.

\begin{tabular}{|c|c|c|c|c|}
\hline Characteristic & Groupings & Female $(n=5)$ & Male $(n=380)$ & Total $(n=385)$ \\
\hline \multirow{5}{*}{ Age in Years } & $18-24$ & $3(60.0 \%)$ & $90(23.7 \%)$ & $93(24.2 \%)$ \\
\hline & $25-34$ & $2(40.0 \%)$ & $130(34.2 \%)$ & $132(34.3 \%)$ \\
\hline & $35-44$ & $0(00.0 \%)$ & $125(32.9 \%)$ & $125(32.5 \%)$ \\
\hline & $55+$ & $0(00.0 \%)$ & $5(1.3 \%)$ & $5(1.3 \%)$ \\
\hline & Mean age & $32.84 \pm 9.90$ & $32.75 \pm 9.64$ & $32.79 \pm 9.75$ \\
\hline \multirow{3}{*}{ Education level } & College & $0(00.0 \%)$ & $25(6.6 \%)$ & $25(6.5 \%)$ \\
\hline & Primary & $1(20.0 \%)$ & $98(25.7 \%)$ & $99(25.7 \%)$ \\
\hline & Secondary & $4(80.0 \%$ & $257(67.6 \%)$ & $261(67.8 \%)$ \\
\hline \multirow{4}{*}{ Marital Status } & Divorced & $2(40.0 \%)$ & $20(5.3 \%)$ & $22(5.7 \%)$ \\
\hline & Married & $0(00.3 \%)$ & $205(53.9 \%)$ & $205(53.2 \%)$ \\
\hline & Single & $3(60.0 \%)$ & $136(35.8 \%)$ & $139(36.1 \%)$ \\
\hline & Widowed & $0(00.0 \%)$ & $19(5.0 \%)$ & $19(4.9 \%)$ \\
\hline \multirow{5}{*}{ Religion } & Catholics & $1(20.0 \%)$ & $98(25.8 \%)$ & $99(25.7 \%)$ \\
\hline & Muslims & $0(00.0 \%)$ & $80(21.1 \%)$ & $80(20.8 .0 \%)$ \\
\hline & Anglicans & $2(40.0 \%)$ & $68(17.9 \%)$ & $70(18.1 \%)$ \\
\hline & Pentecostals & $1(20.0 \%)$ & $69(18.2 \%)$ & $70(18.1 \%)$ \\
\hline & Others & $0(00.0 \%)$ & $35(9.2 \%)$ & $35(9.1 \%)$ \\
\hline
\end{tabular}

\subsection{Sources of VCT Information Amongthe Operators}

The major sources of VCT information among these operators were radio $(89.3 \%)$, other forms of media $90.0 \%$, family members $85.4 \%$, and friends $87.1 \%$ and during marriage counselling $29.5 \%$. Other sources of HIV and VCT information were through health workers and chief Barazas (local meetings held by the administrative chief). Both tested and untested operators have heard of HIV voluntary counselling and testing. On VCT information, $98.8 \%$ of the operators interviewed said they had heard of VCT services.

\subsection{Bivariate Analysis on Factors Associated with Utilization of VCT Services}

Table 2 summarises results of Bivariate analysis using Odds Ratio at significance level of p-value $<0.05$. Five factors were significantly associated with utilization of VCT among BodaBoda operators. Male operators were more likely to go for HIV-VCT test compared to females $(\mathrm{OR}=3.216$, 95\% CI: $1.410-9.644 ; p$-value: 0.001$)$. Operators going to a VCT centre with their sexual partners were also more likely to be tested for HIV as compared to those who went alone
$(\mathrm{OR}=14.643,95 \%$ CI: 3.011-17.624; $p$-value $=0.002)$. Operators who were certain that their test results will be kept confidential were also more likely to go for HIV-VCT test as opposed to those unsure thattheir test resultswill be kept confidential $(\mathrm{OR}=4.79,95 \% \mathrm{CI}: 2.033-8.907 ; p$-value $=$ 0.040). Operators who were aware of presence of VCT services within the region were more likely to go for HIV at VCT compared to those who did not $(\mathrm{OR}=3.318,95 \% \mathrm{CI}$ : 1.262-16.34; $\mathrm{p}$ value 0.022 ). Apparently fear of being seen at a VCT site (OR=0.476, 95\% CI: 0.436-0.816; $p$-value 0.032 ) and having visited a VCT centre in which the operator is known (OR=0.146, 95\% CI: 0.051-0.311; $p$-value 0.002) was associated with testing at a VCT centre. Likewise, participants who had sexual partners and had discussed with partners on HIV testing were significantly 3.61 times more likely to undergo HIV test than those who had never discussed ( $\mathrm{OR}=3.61 ; 95 \% \mathrm{CI}: 1.3-8.7 ; \mathrm{p}=0.015)$. However, participants who had ever practiced sexual intercourse did not significantly differ in VCT uptake from those who had never practiced intercourse $(\mathrm{OR}=1.5 ; 95 \% \mathrm{CI}$ : $0.9-26$; $\mathrm{p}=0.167)$.

Table 2. Bivariate analysis of factors associated with VCT utilization the study participants.

\begin{tabular}{|c|c|c|c|c|c|c|c|}
\hline \multirow[t]{2}{*}{ Variable } & & \multicolumn{6}{|c|}{ Test for HIV at VCT } \\
\hline & & Yes & No & Crude OR & $95 \% \mathrm{CI}$ & & $p$-value \\
\hline \multirow[t]{2}{*}{ Gender } & Male & 200 & 180 & 3.216 & 1.410 & 9.644 & $0.001 *$ \\
\hline & Female & 4 & 1 & & & & \\
\hline \multirow[t]{2}{*}{ Income } & $<5000$ & 254 & 60 & 0.573 & 0.325 & 1.152 & 0.382 \\
\hline & $\geq 5000$ & 30 & 41 & & & & \\
\hline
\end{tabular}




\begin{tabular}{|c|c|c|c|c|c|c|c|}
\hline \multicolumn{2}{|l|}{ Variable } & \multicolumn{6}{|c|}{ Test for HIV at VCT } \\
\hline \multirow[t]{2}{*}{ Marital status } & Single & 90 & 75 & 0.721 & 0.324 & 1.216 & 0.151 \\
\hline & Married & 194 & 26 & & & & \\
\hline \multirow[t]{2}{*}{ Have children } & Yes & 195 & 38 & 1.152 & 0.543 & 1.411 & 0.182 \\
\hline & No & 89 & 63 & & & & \\
\hline \multirow[t]{2}{*}{ Living with spouse } & Yes & 107 & 120 & 0.410 & 0.082 & 5.253 & 0.430 \\
\hline & No & 75 & 83 & & & & \\
\hline \multirow[t]{2}{*}{ Heard of VCT } & Yes & 250 & 80 & 1.231 & 0.245 & 5.203 & 0.160 \\
\hline & No & 34 & 101 & & & & \\
\hline \multirow[t]{2}{*}{ Distance from VCT } & $<2 \mathrm{Km}$ & 256 & 65 & 0.513 & 0.174 & 1.361 & 0.158 \\
\hline & $\geq 2 \mathrm{~km}$ & 28 & 36 & & & & \\
\hline \multirow{2}{*}{ Sexualpartners } & One & 200 & 80 & 1.802 & 0.641 & 2.520 & 0.101 \\
\hline & $>1$ & 84 & 21 & & & & \\
\hline \multirow[t]{2}{*}{ Have visited a VCT centre with partner } & Yes & 201 & 66 & 14.463 & 3.101 & 17.624 & $0.002 *$ \\
\hline & No & 83 & 35 & & & & \\
\hline \multirow[t]{2}{*}{ Fear of being seen at VCT } & Yes & 190 & 40 & 0.476 & 0.436 & 0.816 & $0.040^{*}$ \\
\hline & NO & 94 & 61 & & & & \\
\hline \multirow[t]{2}{*}{ Fear of testing positive } & Yes & 250 & 65 & 0.743 & 0.409 & 1.348 & 0.204 \\
\hline & NO & 34 & 36 & & & & \\
\hline \multirow[t]{2}{*}{ Confidentialityoftest results } & Yes & 270 & 60 & 3.57 & 2.24 & 9.246 & 0.032 \\
\hline & NO & 14 & 41 & & & & \\
\hline \multirow[t]{2}{*}{ Is HIV problem in society } & Yes & 258 & 70 & 2.840 & 0.723 & 7.341 & 0.054 \\
\hline & No & 26 & 31 & & & & \\
\hline \multirow[t]{2}{*}{ Visiting a VCT in which the operator is known. } & Yes & 30 & 76 & 0.146 & 0.051 & 0.311 & $0.002 *$ \\
\hline & No & 154 & 25 & & & & \\
\hline \multirow[t]{2}{*}{ Aware of VCTs within the Coastal Region } & Yes & 257 & 80 & 3.318 & 1.262 & 16.34 & $0.022 *$ \\
\hline & No & 27 & 21 & & & & \\
\hline
\end{tabular}

*Significant at $\mathrm{p}<0.05$ value, $\mathrm{OR}=\mathrm{Odds}$ ratio, $\mathrm{CI}=$ Confidence Interval

\subsection{Logistic Regression of Significant Variables in Bivariate Analysis}

Factors significantly associated with VCT utilisation at bivariate analysis $p$ value $<0.05$ were entered into a logistic regression analysis using backward conditional regression model to assess individual factor effect on VCT utilization. All the factors remained significantly associated with HIVVCT utilisation. Gender (AOR $=3.216$, 95\% CI: 1.381 17.734: $p$-value $=0.033$ ), going to a VCT centre with a sexual partner $\quad(\mathrm{AOR}=14.463, \quad 95 \% \quad \mathrm{CI}: 3.532-23.251: \quad p$ value $<0.001)$ and having confidence that your test results are safe $(\mathrm{OR}=3.579,95 \%$ CI: 2.240-9.246; $p$-value $=0.041)$ were more likely associated with VCT utilization among the operators in Coastal region. Awareness of VCT services within the region was not a likely predictor to VCT utilization in a logistic regression (AOR $=3.561,95 \% \mathrm{CI}$ : $0.267-8.214 ; p$-value $<0.327)$. Having visited a VCT in which the operator is known (AOR $=0.146,95 \% \mathrm{CI}$ : 0.051 0.311 ; $p$-value 0.004 ) and fear of being seen at a VCT site were not associated with testing at a VCT centre (AOR $=0.476$, 95\% CI: $0.476-0.816$; $p$-value 0.035 ) as shown in table 3 .

Table 3. Multivariate analysis of factors associated with VCT utilization.

\begin{tabular}{|c|c|c|c|c|c|c|c|}
\hline \multicolumn{8}{|c|}{ Tested for HIV atVCT } \\
\hline Variable & & Yes & No & AOR & $95 \% \mathrm{C}$ & & $p$-value \\
\hline \multirow{2}{*}{ Gender } & Male & 200 & 180 & 3.216 & 1.381 & 12.734 & $0.033^{*}$ \\
\hline & Female & 4 & 1 & & & & \\
\hline \multirow{2}{*}{ Visiting a VCT with partner } & Yes & 201 & 66 & 14.463 & 3.532 & 23.251 & $<0.001 *$ \\
\hline & No & 83 & 35 & & & & \\
\hline \multirow{2}{*}{ Confidentialityoftest results } & Yes & 270 & 60 & 3.57 & 2.240 & 9.246 & $0.041 *$ \\
\hline & NO & 14 & 41 & & & & \\
\hline \multirow{2}{*}{ Fear of being seen at VCT } & Yes & 190 & 40 & 0.476 & 0.436 & 0.816 & $0.035^{*}$ \\
\hline & NO & 94 & 61 & & & & \\
\hline \multirow{2}{*}{ Visiting a VCT centre in which the operatoris known } & Yes & 30 & 76 & 0.146 & 0.051 & 0.311 & $0.004 *$ \\
\hline & No & 204 & 75 & & & & \\
\hline
\end{tabular}

*Significant at $\mathrm{p}<0.05$ value, $\mathrm{AOR}=$ Adjusted Odds ratio, $\mathrm{CI}=$ Confidence Interval

\subsection{The Association Between Predictor Variables and Consistent Condom Use Among BodaBoda Operators in Coastal Kenya}

In a multivariate logistic regression analysis, variables which were having significant association in the crude analysis were fitted to the multivariate model to determine independent predictors of consistent condom use. Hence the odds of consistent use were about (AOR $=2.01$; 95\% CI: 1.04 2.48) and being secondary and college level were less likely to use condom consistently than primary school education 
with $(\mathrm{AOR}=0.80 ; 95 \% \mathrm{CI}: 0.43,0.85)$ and $(\mathrm{AR}=0.78 ; 95 \%$ CI: 0.42-0.98) respectively. Marital status was other significantly associated with consistent condom use among the respondents. The odds of being single and divorced and widowed were more likely to use condom consistently compared to those who were married. Moreover, individuals who were singled in marital status were more likely to use condom consistently compared to those who were married ( $\mathrm{AOR}=1.51 ; 95 \% \mathrm{CI}: 1.07,2.15)$. Although $60.5 \%$ of the non consistent users of condoms had steady (noncasual) relationships, those that maintained casual relationships were twice more likely than later to use condom inconsistently ( $\mathrm{APOR}=2.13 ; 95 \% \mathrm{CI}$ : 1.5-3.78). Condom attitude and barriers $(\mathrm{CAB})$ significantly $(\mathrm{p}<0.001)$ predicted condom use among the participants with those having positive $\mathrm{CAB}$ being approximately two times (APOR-2.24; 95\%CI: 1.51-4.68) more likely than those with negative $\mathrm{CAB}$ to use condoms consistently. Respondents who reported no alcohol abuse were 1.45 times more likely to use condoms consistently $(\mathrm{AOR}=1.45 ; 95 \% \mathrm{CI}: 1.12-2.75 ; \mathrm{p}=0.013)$ than those who reported consuming alcohol. Consistent condom use was found to be 2 times more among participants whose partners never resisted condom use (AOR $=1.98 ; 95 \%$ CI:1.34$3.67 ; \mathrm{p}=0.011$ ). BodaBoda operators who knew that consistent condom use could protect against STIs were 3.21 fold more likely to use condom consistently than those who reported otherwise (95\%CI: 1.15-4.13; $\mathrm{p}=0.034)$. (Table 4).

Table 4. Multivariate analysis of some selected characteristics and consistent condom utilization in Coastal Region, Kenya.

\begin{tabular}{|c|c|c|c|c|}
\hline \multirow[t]{2}{*}{ Variables } & \multicolumn{2}{|c|}{ Consistent Condom use } & \multirow[t]{2}{*}{ Crude OR (95\% CI) } & \multirow[t]{2}{*}{ Adjusted OR (95\% Cl) } \\
\hline & Yes & No & & \\
\hline \multicolumn{5}{|l|}{ Gender } \\
\hline Female & 2 & 3 & 1.00 & 1.00 \\
\hline Male & 230 & 150 & $2.23(1.03,3.46)^{*}$ & $2.01(1.04,2.48)^{*}$ \\
\hline \multicolumn{5}{|l|}{ Age } \\
\hline $18-24$ & 44 & 49 & 1.00 & 1.00 \\
\hline $35-44$ & 88 & 37 & $0.91(0.61,1.37)$ & $1.09(0.64,1.85)$ \\
\hline $45-54$ & 16 & 14 & $0.66(0.45,0.97)^{*}$ & $0.88(0.49,1.57)$ \\
\hline $55+$ & 2 & 3 & $0.45(0.25,0.59)$ & $0.65(0.39,1.63)$ \\
\hline \multicolumn{5}{|l|}{ Educational status } \\
\hline Primary & 55 & 44 & 1.00 & 1.00 \\
\hline Secondary & 190 & 71 & $0.49(0.45,0.81)^{*}$ & $0.80(0.43,0.85)$ \\
\hline College & 17 & 8 & $0.50(0.23-2.93$ & $0.78(0.42,0.98)^{*}$ \\
\hline Married & 150 & 55 & 1.00 & 1.00 \\
\hline Single & 90 & 49 & $1.37(0.52,3.59)$ & $1.51(1.07,2.15)^{*}$ \\
\hline Divorced & 14 & 8 & $1.13(0.54,2.43)$ & $1.21(0.39,2.71)$ \\
\hline Widowed & 8 & 11 & $1.37(0.52,3.59)$ & $1.39(0.67,3.80)$ \\
\hline \multicolumn{5}{|l|}{ Monthly income } \\
\hline$<5000$ & 220 & 94 & 1.00 & 1.00 \\
\hline$>5000$ & 42 & 29 & $0.65(0.43,1.05)$ & $0.75(0.68,1.52)$ \\
\hline \multicolumn{5}{|l|}{ Types of partners } \\
\hline Married Regular & 25 & 60 & 1.00 & 1.00 \\
\hline Non regular & 80 & 25 & $1.40(1.02,2.52)$ & $0.70(0.34,0.83)^{*}$ \\
\hline Unmarried regular & 60 & 30 & $1.23(0.53,1.65)$ & $0.70(0.61,1.82)$ \\
\hline Prostitutes & 97 & 8 & $1.51(0.82,2.40)$ & $0.69(0.52,1.08)$ \\
\hline \multicolumn{5}{|c|}{ Numbers of partners in your life time } \\
\hline \multicolumn{5}{|c|}{ Condom attitude and barriers } \\
\hline Negative & 98 & 110 & 1.00 & 1.00 \\
\hline Positive & 105 & 72 & $1.49(0.87,1.74)$ & $1.09(0.58,1.73)$ \\
\hline \multicolumn{5}{|l|}{ High risk behaviors } \\
\hline Low & 105 & 150 & 1.00 & 1.00 \\
\hline High & 90 & 40 & $0.176(0.75-0.94)$ & $1.38(1.02-1.89)^{*}$ \\
\hline
\end{tabular}

\subsection{Condom Use}

According to this study, 220 (57.1\%) had used condoms in their life time, $189(49.1 \%)$ used in the last 12 months and $165(42.9 \%)$ had used condoms in the last sexual intercourse.
The prevalence of consistent condom use among the BodaBoda operators of Mombasa County was found to be 123 (31.9\%). Consistent condom use was 97 (25.2\%) of the respondents who had sex intercourse with prostitutes, with non-regular partners 80 (20.8\%), unmarried regular partners 
$60(15.6 \%)$ and $25(6.5 \%)$ had intercourse with their married regular partners. Some of the reasons for not using condoms among the respondents were lack of satisfaction, due to its embracing nature to ask and buy condom, restriction from their religion, condom is not necessary to use and can easily burst (Table 5).

Table 5. Sexual history, types of partners and Condom use of the Respondents in Coastal Region.

\begin{tabular}{lll}
\hline Variables & Frequency & Present(\%) \\
\hline Condom use in the first sex & 150 & 39.9 \\
Yes & 235 & 61.1 \\
No & & \\
Ever use condom & 220 & 57.1 \\
Yes & 165 & 42.9 \\
No & & \\
Condom use in the last 12 months & 189 & 49.1 \\
Yes & 196 & 50.9 \\
No & & \\
Condom in the last month & 250 & 64.9 \\
Yes & 135 & 35.1 \\
No & & \\
Condom use in the last sexual intercourse & 165 & 42.9 \\
Yes & 220 & 57.1 \\
No & & \\
Frequency of condom use in the last & & \\
twelve months & 263 & 68.1 \\
Not consistent & 123 & 31.9 \\
Consistent condom use &
\end{tabular}

\section{Discussion}

It is important to measure coverage of VCT uptake among BodaBoda operators, not only because of their vulnerability to HIV but also because they may experience some obstacles in accessing the VCT services. According to the findings of this study, as long as the male subjects were much numerous than females, theywere more likely to uptake of Voluntary HIV Counseling and testing compared to females. This is contrary to studies done in Ethiopia which found females with higher odds of going for HIV test than their male counter parts [22]. A study in Western Uganda also showed that males had low VCT uptake due to inadequate involvement in HIV prevention programs [23]. However findings in this study were supported by a study done in China by [24] that found higher VCT utilization to be associated with males. Males in general are more likely to go for test because they are more sexually adventurers in nature and sometimes feel unsafe for HIV hence they constantly need to know their status [25]. Distance to the VCT centre has been found to be among the factors that hindered the decision towards VCT uptake. Participants who reported to reside near VCT centre were more likely to undergo VCT testing than those who reported to reside far. Among the reasons given included absence of VCT centre around and lack of knowledge about VCT and its location. A significant number of the respondents reported to be busy with no enough time to go for VCT services. According to this study, the major proportion of the respondents had heard about VCT services and the main source of VCT information was reported to media (Radio). The findings look similar to a study conducted in Ethiopia in which the major proportion of the respondents were found to be aware of the VCT services [26]. Another factor that showed significant association with being tested at a VCT was going to a VCT centre with a partner. Thus, accompaniment with a partner while visiting a VCT centre increased chances of the BodaBoda operators being tested for HIV. [24] reportedthat those living with their partners hadincreased chances of going for HIV-VCT test as opposed to those without. This may result from the psychological support someone expects or gets from their partner hence giving courage to be tested for HIV. People usually feel safe when they know someone is standing by their side. This might have been the reason why those who had visited VCT centres with their partners were more likely to be tested for HIV than those who visited VCT centres alone.

On the other hand, visiting a VCT centre in which the operator is known was likely to discourage HIV testing among the operators. Fear of being seen at a VCT centre was also likely to reduce chances of the operators going for test. This may be due to stigma that is still associated with being HIV positive. This finding is similar to a study conducted in Tanzania-Mwanza, whereby poor response to VCT was associated with fear of stigma 27, 28]. So people shy from going to the VCT as those who visit any such centres are considered to be suspicious of themselves of having contacted HIV hence the need for them to be tested and this may have adverse consequences in their communal relationship [29]. A significant number of the respondents reported fear from anxiety and stress that may result after have come to know that they are HIV positive as among the reasons towards low VCT uptake. However, this is due to the fact they lack knowledge and confidence on how they are going to cope with either of the test results. This findings are similar to a study conducted in Ethiopia, whereby, fear from anxiety and stress was found to be among the main factors that influenced uptake the among the youth [26].

Overall, majority, of the study participants (60.1\%) used condom consistently compared to non-consistent users (39.9\%). The social environments in the BodaBoda operators have significant mixing between groups having high and low sexual risk behaviour patterns. The preponderance of available epidemiologic studies have reported that when used consistently and correctly, condoms are highly effective in reducing both the rate of HIV transmission and other STDs by $80 \%$ to $90 \%[30,31]$ and pregnancy [32]. Majority of the participants in our study reported that they used condoms consistently because their partners welcomed it, compared to the nonconsistent users who felt that condom use with longterm partners was unnecessary. We found in our study that older respondents were more likely than younger ones to use condom consistently, a finding that was similarly noted researchers [33, 34]. This observation may help explain in part why adolescents accounted for the persistently high number aged 15 to 24 years living with HIV disease in Kenya. Other studies have found the reverse to be true: that 
younger subjects were significantly more likely to report frequent and consistent condom use during [35, 36].

According to this study there were factors significantly associated with consistent condom use. We found that males BodaBoda operators were two times more likely than females to use condoms consistently. This study was in line with other studies where the prevalence of consistent condom use was higheramong males compared to females among Cameroonian armed forces and same for civil population too where women females were less likely to report condoms with their sexual partners than men [37]. According to this study, educational status of the BodaBoda operators significantly affected consistent condom use with those with secondary and tertiary levels were less likely to use condoms than primary. The probable reason is that BodaBoda operators with secondary and abovewere mostly older and may be resistant to change and failed to failed to use condom than individuals with primary education who may be friendly to accept ideas and advices to prevent sexual transmitted diseases and HIV/AIDS. Consistent and sustained condom use during sex is very important in the fight against HIV/AIDS and understanding the predictors of condom use can enhance effective interventions to elevate usage. In our study, marital status was significantly associated with consistent condom use, the odds of consistent condom use was higher among single, divorced and widowed than the married. Relationship dynamics also play a significant role in determining condom use. Participants with casual partners were more likely to use condoms inconsistently than those involved in steady relationships. This finding collaborates with those of Chatterjee et al who also noted lower rates of condom use with casual partners in the inner city AfricanAmerican communities [38]. Unprotected sex with a casual partner has been documented as a risk factor for HIV infection among mobile populations [39, 40]. Reasons such as financial dependence on male partners, feeling invincible, low self-esteem coupled with the need to feel loved by a male figure and alcohol and drug abuse have been given for such risky behaviours.

Our study also showed that individuals with multiple sexual partners were less likely to report condom use during their last sexual episode compared to those with one sexual partner. This is of concern since individuals with multiple sexual partners who do not use condoms are at high risk of contracting HIV virus. This findings of studies on condom use in relation to number of sexual partners appear to be inconsistent. Some studies suggest that there is greater condom use among individuals with multiple sex partners [41-43] while others report decreased condom use particularly among women [44] and adolescents [45] with multiple sex partners. A possible explanation for our finding is that individuals with high multiple sexual partners may not perceive the risk of infection and hence do not use condoms. Our study can be construed as a clarion call to programs targeting youth particularly BodaBoda operators that emphasis should be placed not only on condom use at each sexual episode among those with multiple partners but also in limiting the number of sexual partners.

\section{Conclusions}

The study demonstrated the presence considerable gaps in the consistent condom use by the respondents. We found a comparatively high level of condom use among BodaBoda operators that was significantly predicted by marital status, gender, educational status and condom use attitude and barriers. However, consistent condom use was not associated with monthly income and number of sexual partners. Consistent condom use utilization in participants with multiple sexual partners at last sexual episode is still low. In addition, the significant HIV risk behaviors exhibited by participants recorded in the univariate analysis, call for gender-specific intervention programs taking into consideration the predictor variables. Such programs would help to increase awareness about the positive aspects of both condom and VCT uptakes. These are likely to be successful indecreasing sexual risk behaviors in this population. It is also important that such intervention program should emphasize the effectiveness of condoms in preventing the spread of HIV/AIDS, while taking into account the psychosocial factors, social environments and lifestyles prevalent in BodaBoda operators.

\section{Competing Interest}

The authors report no conflicts of interest with respect to authorship and/ or publication of this article.

\section{Authors' Contribution}

This work was carried out in collaboration between all others. Author SAY collected the data, did statistical analysis and drafted the manuscript. MFO and RRS initiated the study and made major contributions to the study design. All authors read and approved the final manuscript.

\section{Acknowledgement}

We thank the Medical Officers of Health, Medical Superintendents, Portreitz, Tudor and Likoni Sub county Hospitals, Mlaleo, Mikandani and Tundor Health Centers who greatly assisted us in this study. Appreciations also goes to BodaBoda Operators who offered good cooperation during the process of data collection. We wish to thank Technical University of Mombasa for partly funding this study.

\section{References}

[1] UNAIDS. (2014). Unaids Report on The global Aids Epidemic.

[2] WHO, 2015.

[3] UNAIDS. (2014). Unaids Report on The global Aids Epidemic. 
[4] National AIDS Control Council (NACC). (2014). Global Facts and Figures: The global AIDS epidemic.

[5] Sunmola, A. M., Olley, B. O and Oso, G. E. (2007). Predictors of condom use among sexually active persons involved in compulsory national service in Ibadan, Nigeria. Health educ Res, 22 (44): 459.

[6] Imade, G., Sagay, A., Egah, E. et al. (2008). Prevalence of HIV and other sexually transmissible infections in ration to lemon lime douching among female sex workers in Jose, Nigeria. Sex health, 5 (1): 55-60.

[7] Joshua, O. A., Olutosin, A. A., Isaac, F. A. et al. (2010). Condom use among antiretroviral therapy patients in Ibadan, Nigeria.

[8] Yallowet al. (2012). Patterns of condom use and associated factors among adult HIV positive clients, North Western Ethiopia.

[9] Ncube, N. M., Akunna, J., Babatunde., et al. (2012). Sexual Risk Behaviour among HIV- positive persons in Kumasi, Ghana. Medical Journal, 46 (1).

[10] Hatzell, T., Feldblum, P., Homan, R. et al. (2003). The female condom: is "just as good" good enough. Sex Transm Dis. 30 (5): 440-441.

[11] Musaba, E., Morrison, C. S., Sunkutu, M. R. et al. (1998). Long-term use of the female condom among couples at high risk of human immunodeficiency virus infection in Zambia. Sex Trans Dist. 25 (5): 260-264.

[12] Sayles, J. N., Pettifor, A., Wong, MD, et al. (2006). Factors associated with self-efficacy for use and sexual negotiation among South African Youth. J Aquir Immune DeficSyndr. 43 (2): 226-233.

[13] Gage, A. J. and Ali, D. (2004). Factors associated with selfreported HIV testing among men in Uganda. AIDS Care, 17(2): 153-165.

[14] Centers for Disease Control and Prevention. (2014). Basic information about HIV and AIDs.

[15] Campbell, O. T and Gandhi, R. T. (2011). Update on human immunodeficiency virus (HIV)-2 infection. Journal of infectious Diseases, 52: 780.

[16] Bateganya M., Abdulwadud, O. A. and Kiene, S. M. (2010). Home-based HIV voluntary counselling and testing (VCT) for improving utilization of HIV testing (Review). The Cochrane Library, 7: 1-28.

[17] UNAIDS. (2013). Unaids Report on The global Aids Epidemic.

[18] Kirunga C. T. and Ntozi James, P. M. (1997). Socio-economic determinants of HIV serostatus: a study of Rakai District, Uganda. Health Transition Review, 7: 175-188.

[19] Oduor A. (2010). Risky liaisons: more than usual business going on in Busia border town. Sex for services puts town on high risk map. Standard on Saturday, 255: 12-13.

[20] Okongo, M., Pickering H., Nnalusiba B., Bwanika, K. and Whitworth J. (1997). Sexual Networks in Uganda: Casual and Commercial sex in a trading town. AIDS Care, 9 (2): 199207.

[21] UNAIDS. (2009). Condoms and HIV prevention: Position statement by UNAIDS, UNFP and WHO.

[22] Omer, S. and Haidar, J. (2009). VCT utilization and associated factors among teachers from Harari Administrative region Ethiopia. Ethiopian Journal of Health Sciences. 23 (3):200205.

[23] Bwambale, M. F., Ssali, N. S., Byaruhanga, S., Kalyyango, N. J., Karamangi, A. C. (2008). Voluntary HIV Counseling and testing among men in rural Western Uganda: Implications for HIV prevention. BMC Public Health. 8: 263.

[24] Rou K., Guan J., Wu Z., Li L., Rotheram M. J., Detels R., Wen Y., Lin C. and Cao H. (2009). Demographic and Behavioural Factors Associated With HIV Testing in China. Journal Acquired Immune Deficiency Syndrome. 50 (4): 432 434.

[25] Karau, P. B., Mueni, S. W., Muriira, G. et al., (2010). Responsiveness to HIV Education and VCT Services among Kenyan Rural Women: A Community-Based Survey. African Journal of Reproductive Health 14(3): 165.

[26] Gatta, A. A. (2011). Knowledge and attitudes towards Voluntary HIV Counseling and Testing services amongst adolescent high school students in addis Ababa Ethiopia. AOSIS Open Journal. 35: 103-8.

[27] Wringe, A., Isidingo, R., Urassa, M., Todd, J., Mbata, D., Maiseli, G. et al. (2007). Trends in uptake of voluntary counseling and testing for HIV in rural Tanzania under widely provision of HIV treatments. Trop Med Int Health. 17 (8):1525 .

[28] Kakoko, D. C. (2006). Voluntary HIV counseling and testing service uptakje among primary school teachers in MwanzaTanzania. AIDS Care. 18:554-560.

[29] Zapka J., Stoddard A., Zorn M., Mccusker J. and Mayer K. (1991). HIV antibody test result knowledge, risk perceptions and behaviour among homosexually active men. Patient Education and Counselling, 18:9-17.

[30] Hearst, N and Chen, S. (2004). Condom promotion for AIDS prevention in the developing world: Is it working? StudFamPlann. 35 (1):39-47.

[31] Weller, S and Davis, K. (2002). The effectiveness of condoms in reducing heterosexual HIV transmission. Cochrane DataSyst Rev.

[32] Davis, K and Weller, S. (1999). The effectiveness of condoms in reducing heterosexual transmission of HIV. Fam Plann Perspect. 31 (6): 272-279.

[33] Adih, W. K and Alexander, C. S. (1999). Determinants of condom use to prevent HIV infection among youth in Ghana. $J$ Adolesc Health.:24 (1):63-67.

[34] Akarro, R. R. (2009). Some factors associated with condom use among bar maids in Tanzania. J Biosoc Sci. 41 (1):125137.

[35] Bobrova, N., Sergeev, O., Grechukhina, T. et al. (2005). Social-cognitive predictors od consistent condom use among young people in Moscow. Perspect Sex Reprod Health. 37 (4): 174-178.

[36] Pendergrast, R. A., DurRant, R. H. et al. (1992). Attitudinal and behavioural correlates of condom use in urban adolescents males. J Adolesc Health. 13:33-39. 
[37] Annie, M. N and Linda, R. F. (2010). Sociodemographic Factors Associated to Condom use in Cameroon Military.

[38] Chatterjee, N., Hossain, G. M., Williams, S. (2006). Condom use with steady and casual partners in inner city AfricanAmerican communities. Sex Trans Infect. 82:238-242.

[39] Adebajo, S., Mafeni, J., Moreland, S. et al. (2002). Knowledge, attitudes and sexual behaviour among Nigerian military concerning HIV/AIDS and STD: Final Technical Report. Abuja, Nigeria.

[40] Essien, J., Monjok, E. M., Ekong, et al. (2010). Correlates of HIV knowledge and sexual behaviours among female military personnel. AIDS Behav.

[41] Mnyika, K. S., Klepp, K., Kvale, G., Ole-Kingori, N. et al. (1997). Determinants of High-risk sexual behaviour and condom use among adults in Arusha, region, Tanzania. Int $J$ STD AIDS. 8:176-83.
[42] Ndinya-Achola, J., Ghee, A. E., Kihara, A. N. et al. (1997). High HIV prevalence, low condom use and gender differences in sexual behaviour among patients with STD-related complaints at a Nairobi primary health care clinic. Int J STD AIDS. 8: 506-4.

[43] Simeon, D. T., Lefranc, E., Brain, B., Wyatt, G. E. (1999). Experiences and socialization of Jamaican men with multiple sex partners. West Indian Med J. 48 (4):212-5.

[44] MacDonald, N. E., Wells, G. A., Fisher, W. A et al. (1990). High risk STD/HIV behaviour among college students. JAMA: 263: 3155-9.

[45] Shafer, M. A and Boyer, C. B. (1991). Psychological and behavioural factors associated with risk of sexually transmitted diseases, including human immunodeficiency virus infection among urban high school students. J Pediatr. 48(4): 212-33. 